\title{
ARTICLES
}

Submitted 20.02.2018. Approved 01.10.2018.

Evaluated by double blind review process.

DOI:http:///dx.doi/10.12660/joscmv11n2p32-45

\section{DO ANALYTICALLY-ORIENTED SUPPLY CHAINS BETTER MANAGE RISKS?}

\begin{abstract}
Risk management has emerged as a field of operations management research due to the greater exposure of organizations to internal and external risks, as a result of globalization, outsourcing, reduction in the number of suppliers, and the need to improve cost and inventory management. Although this subject has received attention in recent years, the relationship between analytical orientation and supply chain risk management is little explored. Thus, this research verifies the impact of analytical orientation over supply chain risk management. A questionnaire was applied with micro, small and medium-sized firms of Brazilian Southeast region, obtaining 111 responses. The structural equation modeling was used for analysis and the main conclusions indicate that analytical orientation has a strong and significant impact over supply chain risk management. In this sense, those supply chains that are more analytical manage their risks better, resulting in lower perception of uncertainty.
\end{abstract}

KEYWORDS | Supply chain risk management, analytical supply chains, analytical orientation, uncertainty, structural equation modeling.

Murilo Zamboni Alvarenga
murilozamboni@hotmail.com

Marcos Paulo Valadares de Oliveira marcos.p.oliveira@ufes.br

Hélio Zanquetto Filho

zanquetto@gmail.com

Washington Romão dos Santos

washington_romao@hotmail.com

Universidade Federal do Espírito Santo, Vitória, ES, Brazil 


\section{INTRODUCTION}

In today's turbulent and uncertain environment, every company in the supply chain is susceptible to an endless number of events that can disrupt or interrupt its operations (Pettit, Fiksel, \& Croxton, 2010; Ponomarov \& Holcomb, 2009; Scavarda, Ceryno, Pires, \& Klingebiel, 2015; Sheffi \& Rice Jr., 2005; Skipper \& Hanna, 2009). Knowing that these events affect performance and can be devastating to the members of the chains (Blackhurst, Craighead, Elkins, \& Handfield, 2005; Chen, 2018), the discussion about risk management in supply chains has grown globally both in the academic and professional arena for its potential to protect companies and chains from the negative effects of internal and external risks (Aqlan \& Lam, 2015; Fahimnia, Tang, Davarzani, \& Sarkis, 2015; Fan \& Stevenson, 2018; Jüttner, Peck, \& Christopher, 2003; Mohammaddust, Rezapour, Farahani, Mofidfar, \& Hill, 2017).

Although the literature explores several factors as drivers of risk management efficiency, such as visibility, collaboration and flexibility (Kilubi \& Haasis, 2015; Lavastre, Gunasekaran, \& Spalanzani, 2012; Li, Fan, Lee, \& Cheng, 2015; Nooraie \& Parast, 2015; Tang, Matsukawa, \& Nakashima, 2012; Tang \& Musa, 2011; Thun \& Hoenig, 2011; Wiengarten, Humphreys, Gimenez, \& McIvor, 2016; Zhao, Huo, Sun, \& Zhao, 2013), the impact of the chains' ability to collect, analyze and transform data into useful knowledge, in order to make decisions based on facts and data, that is, to be analytically oriented, is a point not yet explored in the literature when it comes to the use of this analytical capabilities to optimize risk management results.

The analytical approach involves the use of factbased management to guide management decisions and actions (Ladeira et al., 2016). In this sense, being analytical allows companies to maximize decision-making processes by developing the organization's analysis and response capacity, providing better results, and generating value and efficiency in decision-making (Davenport, 2006; Davenport, Harris, De Long, \& Jacobson, 2001; Laursen \& Thorlund, 2010).

Therefore, analytical chains are those that provide members with useful information, compiled from the immensity of data collected, which facilitates decision-making (Sahay \& Ranjan, 2008). In this sense, it is understood that if the chain is analytically oriented, it will be more efficient in identifying, evaluating, and devising strategies to mitigate and control risks, avoiding the negative impact of unwanted events.

Thus, the present research has one main objective: verify the impact of supply chains analytical orientation on supply chain risk management (SCRM). The following aspects are also explored: a) the uncertainty perception according to both, analytical orientation and risk management levels; $b$ ) the levels of analytical orientantion and supply chain risk management considering firms size.

By proposing and testing a model to verify the existence of a relationship between these two important and emerging topics in the current literature, the research aims at presenting elements that will allow organizations to increase the efficiency of their risk management efforts, avoiding the negative effects that disruptive and disturbing events may entail. Moreover, we propose that chains with higher levels of analytical orientation and better risk management process tend to perceive less uncertainty in relations amongst their members. We also aimed at contributing with scales used to measure these two emerging constructs in the literature.

After this brief introduction, the theoretical framework will be presented, conducting a discussion on risk management, followed by an approach involving analytical orientation in supply chains. In the sequence, a conceptual model will be proposed to verify the constructs' relations. Finally, reflections about the model, data analysis and conclusion, as well as research limitations and suggestions for future studies are presented.

\section{LITERATURE REVIEW}

The theoretical framework will address the issues of supply chain risk management, analytical supply chains, uncertainty and the construction of research hypotheses.

\section{Supply chain risk management}

Organizations have realized the need to manage risks in order to mitigate and prevent them for some time. Despite its relevance, management of supply chain risks is still an unexplored issue in the Brazilian scenario and relatively new on the world stage (Tomas \& Alcantara, 2013; Oliveira, Espindola, \& Marins, 2017, Fan \& Stevenson, 2018). 
Supply Chain Risk Management (SCRM) consists of identifying, assessing and controlling internal and external risks that may affect chain performance to eliminate or reduce the likelihood or impact of events that may disrupt the operations of chain members (Jüttner, Peck, \& Christopher, 2003; Sodhi, Son, \& Tang, 2012).

Unlike traditional risk management, focused on the organizational level alone, SCRM understands that links make organizations dependent on one another and therefore assumes a wider perspective considering the sources of vulnerabilities. Thus, it is focused on the risks associated with the chain, as well as how collaboratively chain participants can manage them (Hallikas, Karvonen, Pulkkinen, Virolainen, \& Tuominen, 2004; Thun \& Hoenig, 2011). In sum, management of risks in supply chains is constituted by the intersection of theories of risk management and supply chain management (Zsidisin \& Ritchie, 2009).

According to Lavastre, Gunasekaran and Spalanzani (2012), SCRM is the combination of three elements: the risk attitude, the instruments used in management, and the techniques used to minimize them. The authors' study pointed out that organizations, when confronted with risks, seek to manage them along with other members of the chain. Thus, transferring the risk and managing it individually, are strategies with little acceptance by managers, considering the French companies studied.

Though being a recent issue, it can be said that there are four main stages of SCRM, typical in most of the literature, namely: (1) risk identification, (2) risk assessment, (3) risk control, 4) risk monitoring. We will define each of them below.

(1) Risk identification: Fundamental and initial phase of risk management in supply chains. The risk events can be identified on an individual company or in chain relationships. Since they may interrupt or disrupt the operations of members of the chain, it is necessary to evaluate them and propose strategies to manage them (Aqlan \& Lam, 2015; Hallikas et al., 2004; Norrman \& Jansson, 2004; Tummala \& Schoenherr, 2011; Zsidisin \& Ritchie, 2009). It is also necessary to identify the connectivity between risks, considering that approaching them individually and developing strategies to mitigate specific risks can increase the probability and the impact of another (Chopra \& Sodhi, 2004).

(2) Risk assessment: Procedure performed to classify each risk identified in step (1) on the basis of probability and impact, in order to elaborate appropriate control strategies (Aqlan \& Lam, 2015; Giannakis \& Papadopoulos, 2016; Hallikas et al., 2004; Norrman \& Jansson, 2004; Tummala \& Schoenherr, 2011; Zsidisin \& Ritchie, 2009).

(3) Control / risk management: This stage consists of developing and implementing, along with members of the chain, strategies to mitigate or prevent the occurrence of risks (Hallikas et al., 2004; Norrman \& Jansson, 2004; Tummala \& Schoenherr, 2011; Zsidisin \& Ritchie, 2009). The commonly used strategies are: risk transfer, risk taking, risk elimination, risk reduction, and other individual analyzes of risks (Giannakis \& Papadopoulos, 2016; Hallikas et al.; 2004). For Thun and Hoening (2011), risk management tools can be divided into reactive and proactive. While proactive tools are focused, most commonly, on reducing the likelihood of occurrence of unwanted events; reactive tools seek to mitigate the negative impact.

(4) Risk monitoring: It monitors SCRM progress of, adding or removing risks from the risk checklist and making new assessments, that is, taking corrective measures according to changes in the technological environment, in the chain, in the customer needs, among others, in order to verify if it is possible to reach the desired level of performance (Hallikas et al., 2004; Tummala \& Schoenherr, 2011).

SCRM, if well elaborated, makes it more difficult to interrupt the organization's operations due to interruptions in the chain, and also prepares them for the occurrence of risks, making them safer and less vulnerable (Norrman \& Jansson, 2004). Thus, Li et al. (2015) found that risk sharing mechanisms, as well as risk information sharing, are important for risk management in supply chains, i.e., joint efforts to manage risks, associated with the chain, result in better financial returns for organizations.

It is assumed that risk management should be managed jointly with chain members, and an efficient SCRM, as discussed in this section, is capable of identifying, assessing, mitigating and monitoring the associated risks and, therefore, will be measured as such, according to Exhibition 1 below. 
Exhibition 1. Measurement Scale for Supply Chain Risk Management (SCRM)

1. Risk management in supply chains (Reflective)

\begin{tabular}{c|l}
\hline Items & Questions \\
\hline S1 & It has formal processes to identify risks. \\
\hline S2 & Strategies are implemented to minimize the impact of risks. \\
\hline S3 & Risks are often assessed by ours members. \\
\hline S4 & Risks are often monitored by ours members. \\
\hline
\end{tabular}

\section{Analytical supply chains}

Satisfactory decision making within the organizational context is not an easy task, requiring analytical skills from individuals, organizations and networks of organizations to process information, look for alternatives, and predict consequences for designing actions (Simon, 1979). In this scenario, the use of data has become as ubiquitous as the need to use analytical methods and processes to extract useful information. Therefore, it is precisely from this need that the studies on the subject emerge Analytics.

The terms Business Intelligence (BI), Business Analytics (BA) and Big Data Analytics (BDA) are often used in similar and even interchangeable contexts. Although they present common characteristics, it is possible to delineate some differences that need to be made clear to avoid confusion among the concepts. Davenport (2014) differentiates these terms from a historical perspective. BI focuses on tools to support data-driven decisions, with emphasis on extracting information and reporting. On the other hand, BA encompasses the use of statistical and mathematical skills, aligned with IT skills and business insights for decision-making. Recently, the term Big Data has become more popular because of the large amount of data, structured or unstructured, produced continuously, that can be used to discover hidden patterns, correlations, and useful information.

We define Business Analytics (BA) based on Laursen and Thorlund (2010), as "making the right media available for decision at the right time and for the right people", and it can be seen as an information system composed of: technological elements responsible for collecting, storing and providing information; human skills; and business processes. If all organizations can access some information through simple statistical techniques, the analytical skills go even further, because, combined with information systems; they provide more sophisticated information (Davenport, 2006).

However, as pointed out by Davenport et al. (2001), sophisticated analysis tools as well as investment in technology are not enough for organizations to transform data into knowledge, hence into value, and the human capacity to analyze, interpret, generate and act on the insights is critical to drive results from this complex process of transformation.

This thought is aligned with the arguments by Laursen and Thorlund (2010) that emphasize the importance and responsibility of decision makers to analyze the information obtained through information systems and turn them into useful knowledge to improve or develop business processes and, consequently, to generate value.

Therefore, analytical capabilities consist of a set of analytical methods and tools (Acito \& Khatri, 2014), involving statistics, information technology and business knowledge that provide the opportunity to deliver large volumes of data through organization, availability, analysis and interpretation, taking into account the reality and the specifics of the business, enabling a rapid response to environmental changes (Teo, Nishant, \& Koh, 2016).

Once organizations have used analytical tools such as statistical and quantitative data analysis, explanatory models, and data analysis for decision-making, business processes will be affected by changes and reorganizations, making routines more efficient and generating more value than at an earlier time (Bronzo et al., 2013). However, this requires structuring of collected data for them to be transformed into analytical knowledge, which can be fully explored and used in decision-making processes. 
The study of Davenport (2006) with 32 organizations found that analytical capabilities provide organizations with mechanisms to enable them to improve pricing, identify potential customers and develop new products. Similarly, Bronzo et al. (2013) have found statistically significant results for the impact of using Analytics on financial, learning/growth, market/consumer, and organizational process capabilities.

More specifically to the present study, analytically oriented supply chains are defined as those in which their members use a set of analytical methods and tools to make better decisions regarding the flow of materials through the chain, which can be descriptive, predictive or prescriptive (Souza, 2014). Similarly, Sahay and Ranjan (2008), argue that analytical chains allow, for example, the identification of opportunities of cost reduction.

Thus, analytical supply chains use analytical methods and tools - involving statistics, information technology, and management knowledge - to turn large volumes of data into useful information to support business decisions. Through the analytical approach it is possible to map scenarios, identify the impact of expected and unexpected events, minimize inventories and streamline product flow, providing benefits to key management processes (planning, supplying, producing, delivering, returning), minimizing asymmetries (Chae, Olson, \& Sheu, 2013; Chae \& Olson, 2013; Davenport, 2006; Souza, 2014).

Empirically, Trkman, McCormack, Oliveira, and Bronzo (2010) verified that the use of a set of approaches and procedures for organizations to gather information, understand it and be able to apply solutions in the areas of Supply Chain Reference Model (SCOR) i.e., the use of the analytical approach in critical supply chain processes, results in better chain performance in addition to the findings that the relationship between analytical capabilities and performance is moderated by the organization's information systems. Still, Chae, Olson, and Sheu (2013) found the impact of analytically oriented chains on the individual performance of members and Zhu, Song, Hazen, Lee, and Cegielski (2018) explored the impact of analytics on the transparency of chains.

For the aims of this study, the analytical orientation measure in supply chains was based on Trkman et al. (2010) scale, and analytically oriented chains are considered as those in which their members efficiently process data through quantitative analysis in order to make fact-based decisions regarding chain processes. Exhibition 2 presents the proposed indicators.

Exhibition 2. Measurement scale analytical guidance in supply chains

\begin{tabular}{c|l}
\hline \multicolumn{2}{l}{ 2. Analytical orientation in supply chains. (Reflective) } \\
\hline Items & Questions \\
\hline A1 & The quantitative analysis of the data directs the managerial actions. \\
\hline A2 & $\begin{array}{l}\text { Members use the knowledge generated from the quantitative data analysis to improve } \\
\text { the chain's processes. }\end{array}$ \\
\hline A3 & To support management decisions, members are able to process data efficiently. \\
\hline
\end{tabular}

\section{Uncertainty}

As in any day-to-day activity, as well as for each organization, innumerable are the events of risks and uncertainties inherent in supply chains. In general, the literature classifies such risk events as internal and external. External risks are related to the impacts on the environment caused by natural or human-made disasters that affect, directly or indi- rectly, supply chains (Fahimnia et al., 2015; Thun \& Hoenig, 2011). Earthquakes, tsunamis, terrorist attacks, hurricanes, as well as political instability and economic crises are characterized as examples of this typology of risks. Internal risks, according to Aguiar, Tortato, and Gonçalves (2014) are present in the organizational environment, and these are related to the activities of the organization and the 
relationships between different companies in the chain. Examples of internal risks are an oscillation in demand, information delay, available capacity, and supplier inflexibility.

Chopra and Sodhi (2004) categorized risks into: disruptions, delays, system, forecasts, intellectual property, procurement, receivables, inventory, and capacity. In all, the nine risk categories added up to 28 risk drivers, demonstrating the range of risks in the chains. Contributing to the advancement of the theme, Aguiar, Tortato, and Gonçalves (2014) developed risk constructs for supply chains composed of the following dimensions: external environment; business processes; organizational structure; management components; internal environment; comprising 51 risk factors.
For Fahimnia et al. (2015), while some risks can be prevented, others must be mitigated. It should be emphasized that internal risks are more likely to occur, while external ones have greater impacts on the chains because they are usually associated with events with severe consequences (Thun \& Hoenig, 2011; Kırılmaz \& Erol, 2017; Revilla \& Saenz, 2017).

To measure uncertainty, this study based on the argument that in supply chains affected by environmental uncertainties, their members perceive greater degree of uncertainty in the relationships they are involved, that is, in source and delivery. Thus, to measure the uncertainty perceived by managers, the following indicators were used, as shown in Exhibition 3, below:

Exhibition 3. Uncertainty Indicators

\section{Uncertainty \\ Items Questions}

IA1 There is uncertainty about the mix of demand. (variety of products)

IA2 There is uncertainty about the volume of demand.

IA3 There is uncertainty regarding the supply of materials. (Time and volume).

\section{Hypotheses}

From the preceding arguments, it is expected that if the chain is analytically oriented, its members will be able to process information more efficiently, i.e. "... capture, integrate and analyze data and information, and use the insights generated in the context of organizational decision-making" (Cao, Duan \& Li, 2015, p. 385), favoring risk management through greater prevention capacity (Ittmann, 2015).

Tang and Musa (2011) argue the need to develop a quantitative approach to manage supply chain risks, and lack of information can undermine chain decision-making. Thus, it is necessary to improve computational efficiency. In addition, it is argued by Tummala and Schoenherr (2011) that data management enables you to query, store and add risk information, assisting in the management and enhancement of SCRM.
Also, the analytical orientation in supply chains is essential for the use of management tools (Ittmann, 2015), characterized as descriptive, predictive and explanatory techniques. Some examples are: "and if" (Hallikas et al., 2004; Lavastre et al., 2012; Tummala \& Schoenherr, 2011); risk diagrams (Hallikas et al., 2004; Lavastre et al., 2012); cause and effect analyzes (Tummala \& Schoenherr, 2011); mapping processes (Lavastre, Gunasekaran, \& Spalanzani, 2012).

In this way, it is understood that in order to identify, evaluate, propose mitigation strategies and monitor risks efficiently, in addition to collaboration, flexibility, and visibility, supply chains are required to develop analytical orientation. Thus, we have the following research hypotheses:

H1: Analytical orientation positively impacts risk management in supply chains.

The research model is shown in Figure 1. 
Figure1. Research Model

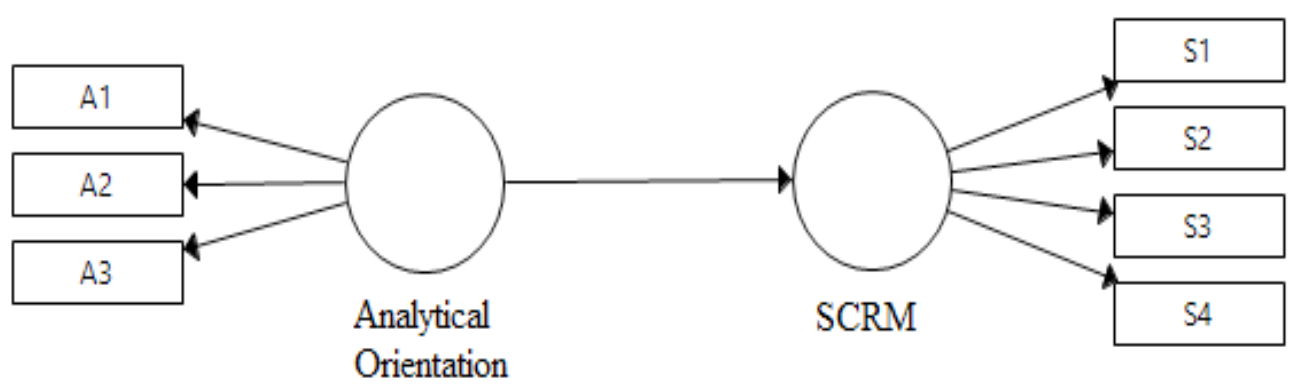

Based on the theoretical framework, it is understood that being analytical leads to a better understanding of the environment, reducing the perception of uncertainty. According to Galbraith (1974), the more complex and turbulent the environment, the higher the need for information processing. Likewise, identifying risks, assessing them, mitigating them and monitoring them, make the perception of uncertainty decrease, as companies feel capable of better managing environmental changes and, therefore, do not perceive them as uncertainties. Consequently, those supply chains that are more analytical or that better manage their risks reduce their uncertainty perception.

H2: Supply chains with higher level of analytical orientation have lower perception of environmental uncertainty than those with lower level of analytical orientation.

H3: Supply chains with higher level of risk management have lower perception of environmental uncertainty than those with lower level of risk management.

\section{METHODOLOGY}

Considering the purpose of the research, a questionnaire was developed to collect data referring to the constructs presented in the conceptual model. For the development of the questionnaire, a structured bibliographical review was carried out to delimit the constructs and operationalize them. In the next phase, a pre-test of the survey instrument was conducted in order to eliminate ambiguities and to validate the instrument. To do this, the questionnaire, prepared on the SurveyMonkey platform, was sent to ten professionals responsible for the production / supply chain of industries belonging to the research base, requesting them to report any doubts or issues experienced when answering to the questionnaire. Respondents considered the ques- tionnaire quick and easy to understand, reporting no problems in answering it.

Thus, the questionnaire comprised 11 questions regarding the constructs, besides four items that made it possible to characterize the sample and served as control variables. In the questions related to the constructs, the 7-point Likert scale was used, with 1 equal to 'totally disagree' and 7 equal to 'totally agree'.

One of the difficulties of the research was to obtain a reliable database for sending the questionnaires. The best way was to use the industrial lists, which are vehicles for dissemination of companies organized through a partnership between the Industrial and Business Center of Minas Gerais and the Brazilian Editor of Special Guides (EBGE) with the federations of industries of the states involved. Considering that the registered population had 8,667 micro, small and medium-sized industries, it was decided to send to questionnaires to the whole cadastral base, given the feasibility of data collection, and considering the low costs of conducting the survey. It is worth emphasizing here that the authors of this research carried out the organization of this database to deal with problems of omissions and redundancies. Nevertheless, the difficulties to identify the population and obtain access to respondents should be mentioned, since it is not possible to guarantee that the total number of active companies in the list is correct, nor the identification of companies, because their emails could be no longer valid.

The data were collected in two stages from August to November 2017. First, an electronic contact was made with each of the registered companies in order to request the e-mail of the person responsible for the production, purchase, marketing or supply chain management of organizations. Considering that these were the subjects of the research, this proce- 
dure was done to improve the quality of the questionnaire responses. This phase resulted in the return of 142 emails. In the second phase a reminder was sent for these emails with the link of the questionnaire to all the other emails registered on the databases, asking those who received the e-mail to forward it to the professionals who performed the already mentioned activities, as these were the subjects of the research. After all, 111 companies responded to the survey.

So, one of the limitations of the work is highlighted, since there is no guarantee that the available sample represents the population, due the amount of errors in the original list of companies. However, considering the descriptive statistics presented in section 3.1, a similar percentage for the three states is observed. There is also predominance of micro and small companies, reflecting the predominance in the Brazilian industry. Complementarily, approximately $83 \%$ of respondents are presidents, directors or managers, thus confirming that the survey subjects were reached. Moreover, given the hierarchical level of the respondents, good quality of responses can be expected. Thus, it is believed that this limitation did not generate significant bias in the conclusions.

The structural equations modeling was used to analyze the data. According to Hair, Black, Babin, Anderson, and Tatham (2009), the Structural Equations Modeling (SEM) provides the possibility of efficiently estimating a series of separate multiple regression equations, simultaneously calculating all of them, and using the relationships between the constructs. SEM empirically tests a set of dependency relationships through a model that operationalizes theory and provides the representation of relationships through a path diagram. The research aims at studying the relationships between constructs of analytical orientation in supply chains and the management of risks in supply chains. Therefore, the structural equations modeling and the statistical method of partial least squares (PLS) using the software SmartPLS 3 were used.

PLS does not require large samples, does not generate identification problems and does not assume that the distribution is normal across the measurement variables (Chin, Marcolin, \& Newsted, 2003). To calculate the sample size, we used the criterion of the number of arrows of a construct that points to another construct (Hair, Sarstedt, Ringle, \& Gudergan, 2017). As previously reported, the database was composed of 111 cases, supporting the analysis.

\section{Sample description}

Of the 111 industries that made up the sample, 34 were located in Espírito Santo (30.63\%), 38 in Minas Gerais (34.23\%) and 39 in Rio de Janeiro (35.10\%).

Regarding company size, micro (42.34\%) and small industries $(40.54 \%)$ predominated. The remaining cases of the sample comprised medium-sized industries $(17.12 \%)$. As a criterion of classification, the approach of the industrial registries themselves and SEBRAE was used to classify the size of industries based on the number of employees. Thus, companies with up to 19 employees were ranked as micro, from 19 to 99 as small, from 100 to 499 as medium size. Thus, $17.12 \%$ of the participating industries were classified as medium, $40.54 \%$ as small and $42.34 \%$ as micro.

About the profile of the respondents, 15 serve as chair (13.51\%), 35 are directors (31.53\%), 44 are managers (39.64\%), 8 are assistants (7.21\%) and 9 work in positions other than those specified (8.11\%). Of these, 51 have the primary function of production (45.95\%), 26 of purchase (23.42\%), 14 of marketing / sales (12.61\%) and 20 of other functions (18.02\%).

\section{Data analysis}

The first step before running the structural equation model is to analyze the measurement model. Firstly, we investigated the reflexive constructs (analytical orientation and SCRM). According to Hair et al. (Cronbach's Alpha and Compound reliability), convergent validity (AVE and loads) and discriminant validity (Fornell \& Lacker's Table).

By analyzing the reliability and internal consistency of constructs, it was observed that the values obtained from Cronbach's Alpha and composite reliability guarantee the internal reliability. Furthermore, all loads obtained values greater than 0.703 , and the average variance extracted (AVE) of constructs were higher than 0.70 , assuring the convergent validity. In addition, discriminant validity between constructs was verified, since the square root of the AVE of constructs was proven to be greater than the correlation between them. The results of the reflective measurement model are shown in Table 1. 
Table1. Results of the reflective measurement model

\begin{tabular}{|c|c|c|c|c|c|c|}
\hline \multirow{3}{*}{ Latent variable } & \multirow{3}{*}{ Index } & \multicolumn{2}{|c|}{ Convergent validity } & \multicolumn{2}{|c|}{$\begin{array}{l}\text { Reliability and internal } \\
\text { consistency }\end{array}$} & \multirow{2}{*}{ DiscriminatingValidity } \\
\hline & & Load & AVE & $\begin{array}{l}\text { Compositere- } \\
\text { liability }\end{array}$ & $\begin{array}{l}\text { Alpha de } \\
\text { Cronbach's }\end{array}$ & \\
\hline & & $>0.70$ & $>0.50$ & $\begin{array}{c}>0.60 \text { até } \\
0.95\end{array}$ & $0.60-0.90$ & \\
\hline \multirow{3}{*}{ Analytical orientation } & A1 & 0.773 & \multirow{3}{*}{0.703} & \multirow{3}{*}{0.876} & \multirow{3}{*}{0.790} & \multirow{7}{*}{ Yes } \\
\hline & $\mathrm{A} 2$ & 0.877 & & & & \\
\hline & A3 & 0.862 & & & & \\
\hline \multirow{4}{*}{ SCRM } & S1 & 0.820 & \multirow{4}{*}{0.749} & \multirow{4}{*}{0.923} & \multirow{4}{*}{0.888} & \\
\hline & $\mathrm{S} 2$ & 0.868 & & & & \\
\hline & $\mathrm{S3}$ & 0.903 & & & & \\
\hline & S4 & 0.869 & & & & \\
\hline
\end{tabular}

After ensuring that the measurement models are valid and reliable, the next step was to analyze the structural model by means of its predictive relevance and the relation between the constructs, being evaluated the following steps: significance and relevance of the existing relationship in the structural model, the $\mathrm{R}^{2}$ level; predictive relevance $\mathrm{Q}^{2}$ (Hair et. al., 2017).
The significance and relevance of the path coefficients were analyzed, verifying if they were statistically different from zero. Thus, it became necessary to perform the Bootstrapping procedure with 5,000 subsamples. Table 2 shows the results of significance and relevance tests of the path coefficients.

Table2. Significance test results

\begin{tabular}{l|c|c|c|c}
\cline { 2 - 4 } & SAMPLE MEAN & $\begin{array}{l}\text { STANDARD } \\
\text { DEVIATION }\end{array}$ & $\boldsymbol{t}$ & $\boldsymbol{p}$ \\
\hline Analytical orientation -> SCRM & 0.596 & 0.065 & 9.132 & 0.000 \\
\hline
\end{tabular}

The results indicate that the analytical orientation construct has a positive and statistically significant impact on the management of risks in supply chains since the relationship showed a path coefficient of 0.596 and p-value of 0.000 . Thus, the research hypothesis has been confirmed, indicating that supply chains where their members use quantitative data analysis to make facts-based decisions are also more efficient in managing risks.

Another measure widely used to evaluate structural models is $\mathrm{R}^{2}$, and it is responsible for representing the effects of the combination of exogenous variables on the endogenous variable (Hair et al., 2017).
The results indicate that $35.50 \%$ of the variation in the supply chain risk management construct is derived from the variation of the analytical orientation construct. Although it can be pointed out as a medium value, it is understood to be a significant and relevant result because there are several other factors not addressed in the present study that affect SCRM. The adjusted $\mathrm{R}^{2}$ of the model was $34.90 \%$.

Finally, the $\mathrm{Q}^{2}$ of the model, obtained through the blindfolding procedure with omission distance of seven was 0.245 , demonstrating that the model has predictive capacity. According to Hair et al. (2017), $\mathrm{Q}^{2}$ greater than zero represents that the exogenous 
construct is, in fact, capable of predicting the endogenous construct.

\section{Hypotheses tests}

In order to form only two groups of chains (an environment with low uncertainty $\mathrm{x}$ high uncertainty); a cluster analysis was performed in SPSS software with the average of the uncertainty variables (IA1, IA2, and IA3). Out of all companies, 35 were classi- fied with a low perception of uncertainty (one) and 76 with a high perception of uncertainty (two). In addition, to determine the degree of analytical orientation and the degree of risk management, the averages of the indicators of each construct were used.

From the transformations, a comparison, shown in Table 3, was drowned between the averages of the constructs for both industries with high uncertainty perception and industries with low uncertainty.

Table3. Test for difference of mean uncertainty

\begin{tabular}{|c|c|c|c|c|c|c|}
\hline CONSTRUCT & $\begin{array}{l}\text { UNCERTAINTY } \\
\text { PERCEPTION }\end{array}$ & $\mathbf{N}$ & MEAN & $\begin{array}{l}\text { STANDARD } \\
\text { DEVIATION }\end{array}$ & STD. ERROR & $\begin{array}{l}\text { WELCH } \\
\text { TEST }\end{array}$ \\
\hline \multirow{3}{*}{ Analytical orientation } & Low & 35 & 5.47 & 0.86 & 0.15 & \multirow{3}{*}{0.006} \\
\hline & High & 76 & 4.90 & 1.21 & 0.14 & \\
\hline & Total & 111 & 5.08 & 1.14 & 0.11 & \\
\hline \multirow{3}{*}{ SCRM } & Low & 35 & 5.10 & 1.01 & 0.17 & \multirow{3}{*}{0.002} \\
\hline & High & 76 & 4.38 & 1.35 & 0.15 & \\
\hline & Total & 111 & 4.60 & 1.29 & 0.12 & \\
\hline
\end{tabular}

The results indicate that supply chains that perceive less uncertainty have higher average of both analytical orientation and risk management, comparing with those with high perception of uncertainty. It was also verified whetherthese two groups of chains (low perception of uncertainty $\mathrm{x}$ high perception of uncertainty) are statistically different regarding analytical orientation and risk management in supply chains, and Welch test was performed for equality of mean. The Welch test is used when it is not possible, through the Levine test, to verify the homogeneity of variances.

It is possible to verify that both the analytical orientation and the SCRM are statistically different across the groups. Thus, it is verified that companies that have both higher degree of analytical orientation and SCRM have lower perception of envi- ronmental uncertainty, whereas the contrary is also true. Therefore, hypotheses 2 and 3 were confirmed, corroborating the literature.

In addition, it was verified whether larger companies have both higher level of analytical orientation and better risk management. This procedure aimed at verifying if, regardless of size, industries are concerned with using quantitative data analysis in order to make better decisions involving the chain and if they understand the existence of risks associated with them and the need to manage them.

The results are presented in Table 4, as previously noted, when the size increases, the levels of analytical orientation and risk management also increase. Nevertheless, this difference was not statistically significant when conducting the tests for differences of averages. 
Table4. Test for medium-sized difference

\begin{tabular}{|c|c|c|c|c|c|c|c|}
\hline CONSTRUCT & SIZE & $\mathbf{N}$ & MEAN & $\begin{array}{l}\text { STANDARD } \\
\text { DEVIATION }\end{array}$ & $\begin{array}{l}\text { DEFAULT } \\
\text { ERROR }\end{array}$ & $\begin{array}{l}\text { LEVINE } \\
\text { SIG. }\end{array}$ & $\begin{array}{c}\text { TEST OF AVERAGE } \\
\text { SIG. }\end{array}$ \\
\hline \multirow{4}{*}{$\begin{array}{l}\text { Analytical } \\
\text { orientation }\end{array}$} & until 19 & 47 & 4.80 & 1.37 & 0.20 & \multirow{4}{*}{0.013} & Welch \\
\hline & $20-99$ & 45 & 5.21 & 0.91 & 0.14 & & \multirow{3}{*}{0.75} \\
\hline & $100-499$ & 19 & 5.44 & 0.82 & 0.19 & & \\
\hline & Total & 111 & 5.08 & 1.14 & 0.11 & & \\
\hline \multirow{4}{*}{ SCRM } & until 19 & 47 & 4.39 & 1.42 & 0.21 & \multirow{4}{*}{0.059} & ANOVA \\
\hline & $20-99$ & 45 & 4.59 & 1.22 & 0.18 & & \multirow{3}{*}{0.68} \\
\hline & $100-499$ & 19 & 5.16 & 0.98 & 0.22 & & \\
\hline & Total & 111 & 4.60 & 1.29 & 0.12 & & \\
\hline
\end{tabular}

\section{DISCUSSION AND CONTRIBUTIONS}

The results obtained, presented in Figure 2, are in line with the expectations presented initially in this study and with the construction of the central re- search hypothesis. It was observed that the supply chain analytical orientation has a positive, significant and robust impact on SCRM. Still, it can explain $35.50 \%$ of its variation.

Figure2. Result of the structural model

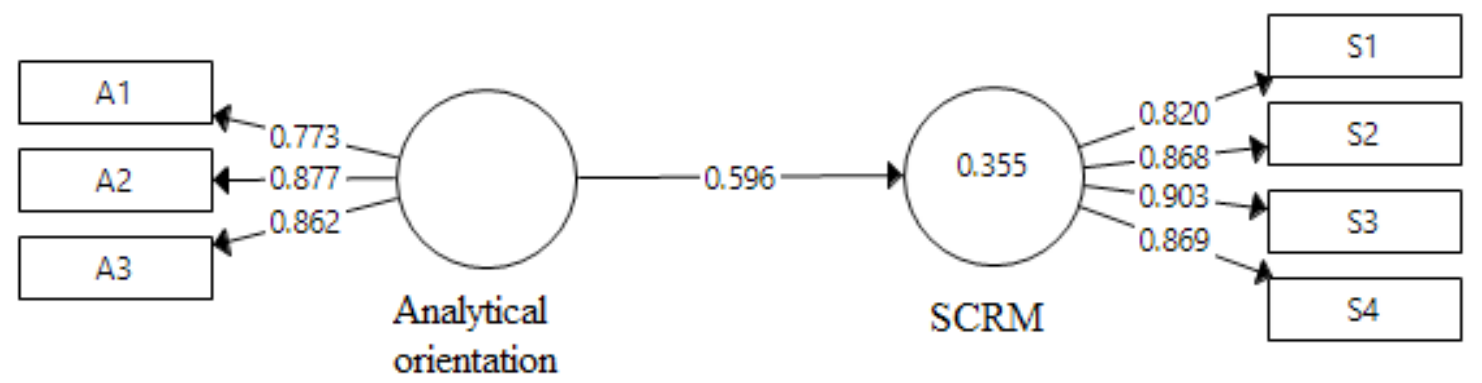

As a practical implication, the results show that if supply chains want to survive from disruptions caused by the imense number of risks inherent in them - that makes impossible to produce the right quantity to the right location at the right time and in a profitable way - its members must be able to process data efficiently and, as a consequence of being analytically oriented, better manage risks. In this way, analytical approach to decision making allows supply chain members to identify possible sources of risk and to propose appropriate strategies to mitigate them, allowing them to avoid risks, maintain or recover operations in case they occur.

From a conceptual and complementary point of view, it is interesting to note that the majority of respondents hold high hierarchical positions in organizations, which may lead one to infer that they have consistent professional experience. Consider- ing that risk management could be influenced by the manager's experience, it could be assumed that the impact identified here would be a "spurious" impact. However, considering that the experience has certain homogeneity, in the sample surveyed, the relevance of this finding is further verified, since data-based decision making was proven to improve risk management in the supply chain.

Although it is not the primary objective of this research, it was observed that there is no difference across levels of analytical orientation and risk management for micro, small and medium-sized companies, that is, regardless of size, companies are awareness about the importance of making decisions based on data and with the adoption of risk management procedures. This can be a consequence of the better training of industrial managers, micro and small companies, and can also happen due to 
the broad access to technologies and computational methods nowadays.

In a complementary way, this study showed that those chains with higher degree of analytical orientation or greater degree of risk management present lower level of uncertainty perception. This result makes sense conceptually because a greater capacity to use the data for decision making, and the understanding that the uncertainty is manageable imply greater security for the members of the supply chain, that's why the perceived risk would be smaller. In this sense, what would be considered uncertain might not be uncertain depending on the levels of analytical orientation and risk management. Therefore, it is concluded that both constructs, the analytical orientation in supply chains and the SCRM, imply less uncertainty perception in their operations because the members of the chain are more aware of their processes and the risks associated with them.

Conceptually, this article intends to contribute to the literature by relating two constructs, relevant to the management of supply chains, considering that the environment is becoming increasingly uncertain.

\section{Limitations and future research}

As main limitation, the survey was answered by only one member of the chain, who gave his opinion about the chain as a whole, where the ideal would be to obtain answers from at least one supplier, one manufacturer and one buyer belonging to the same chain. Another limitation is the low number of medium-sized companies among those that participated in the research.

For future research, we suggest verifying the role of analytical orientation in the relationship between risk management and other capabilities that affect the construct, and if analytical orientation and risk management help supply chains recover from unexpected events by improving resilience. As a suggestion, new constructs can be included to increase the explanatory power to predict supply chain risk management, such as visibility, collaboration, and flexibility.

\section{REFERENCES}

Acito, F., \& Khatri, V. (2014). Business analytics: Why now and what next? Business Horizons, 57(5), 565-570.

Aqlan, F., \& Lam, S. S. (2015). A fuzzy-based integrated frame- work for supply chain risk assessment. International Journal of Production Economics, 161, 54-63.

Aguiar, E. C., Tortato, U., \& Gonçalves, M. A. (2014). Identificação dos riscos em cadeias de suprimentos: um estudo introdutório com empresas da região Sul do Brasil. Revista de Negócios, 19(4), 64-83.

Blackhurst, J., Craighead, C. W., Elkins, D., \& Handfield, R. B. (2005). An empirically derived agenda of critical research issues for managing supply-chain disruptions. International Journal of Production Research, 43(19), 4067-4081.

Bronzo, M., de Resende, P. T. V., de Oliveira, M. P. V., McCormack, K. P., de Sousa, P. R., \& Ferreira, R. L. (2013). Improving performance aligning business analytics with process orientation.International Journal of information management, 33(2), 300-307.

Cao, G., Duan, Y., \& Li, G. (2015). Linking business analytics to decision making effectiveness: A path model analysis. IEEE Transactions on Engineering Management, 62(3), 384-395.

Chae, B. K., Olson, D., \& Sheu, C. (2013). The impact of supply chain analytics on operational performance: A resourcebased view. International Journal of Production Research, 52(16), 4695-4710.

Chae, B., \& Olson, D. L. (2013). Business Analytics for Supply Chain: a Dynamic-Capabilities Framework. International Journal of Information Technology \& Decision Making, 12(1), 9-26.

Chen, H. L. (2018). Supply chain risk's impact on corporate financial performance. International Journal of Operations \& Production Management, 38(3), 713-731.

Chin, W. W., Marcolin, B. L., \& Newsted, P. R. (2003). A partial least squares latent variable modeling approach for measuring interaction effects: Results from a Monte Carlo simulation study and an electronic-mail emotion/ adoption study. Information Systems Research, 14(2), 189-217.

Chopra, S., \& Sodhi, M. S. (2004). Managing risk to avoid supply-chain breakdown. MIT Sloan Management Review, 46(1), 52-61.

Davenport, T. H. (2006). Competing on Analytics. Harvard Business Review. Retrieved from https://hbr.org/2006/01/ competing-on-analytics

Davenport, T. H. (2014). How strategists use "big data" to support internal business decisions, discovery and production. Strategy \& Leadership, 42(4), 45-50.

Davenport, T. H., Harris, J. G., De Long, D. W., \& Jacobson, A. L. (2001). Data to knowledge to results: Building an analytic capability. California Management Review, 43(2), 117-138.

Fahimnia, B., Tang, C. S., Davarzani, H., \& Sarkis, J. (2015). Quantitative models for managing supply chain risks: A review. European Journal of Operational Research, 247(1), 1-15.

Fan, Y., \& Stevenson, M. (2018). A review of supply chain risk management: Definition, theory, and research agenda. International Journal of Physical Distribution \& Logistics Management, 48(3), 205-230. 
Galbraith, J. R. (1974). Organization design: An information processing view. Interfaces, 4(3), 28-36.

Giannakis, M., \& Papadopoulos, T. (2016). Supply chain sustainability: A risk management approach. International Journal of Production Economics, 171, 455-470.

Hair, J. F., Black, W. C., Babin, B. J., Anderson, R. E., \& Tatham, R. L. (2009). Análise multivariada de dados (6th ed.). Porto Alegre, RS: Bookman.

Hair, J. F., Sarstedt, M., Ringle, C. M., \& Gudergan, S. P. (2017). Advanced issues in partial least squares structural equation modeling. SAGE Publications.

Hallikas, J., Karvonen, I., Pulkkinen, U., Virolainen, V. M., \& Tuominen, M. (2004). Risk management processes in supplier networks. International Journal of Production Economics, 90(1), 47-58.

Ittmann, H. W. (2015). The impact of big data and business analytics on supply chain management. Journal of Transport and Supply Chain Management, 9(1), 1-9.

Jüttner, U., Peck, H., \& Christopher, M. (2003). Supply Chain Risk Management: Outlining an Agenda for Future Research. International Journal of Logistics: Research and Applications, 6(4), 197-210.

Kilubi, I., \& Haasis, H. D. (2015). Supply chain risk management enablers-A framework development through systematic review of the literature from 2000 to 2015. International Journal of Business Science and Applied Management, 10(1), 35-54.

Kırılmaz, O., \& Erol, S. (2017). A proactive approach to supply chain risk management: Shifting orders among suppliers to mitigate the supply side risks. Journal of Purchasing and Supply Management, 23(1), 54-65.

Ladeira, M. B., Resende, P. T. V. de, Oliveira, M. P. V. de McCormack, K., Sousa, P. R. de, \& Ferreira, R. L. (2016). Os efeitos da abordagem analítica e da gestão orientada para processos sobre o desempenho organizacional de micro e pequenas empresas brasileiras dos setores da indústria e de serviços. Gestão \& Produção, 23(32), 486-502.

Laursen, G. H., \& Thorlund, J. (2010). Business analytics for managers: Taking business intelligence beyond reporting. John Wiley \& Sons.

Lavastre, O., Gunasekaran, A., \& Spalanzani, A. (2012). Supply chain risk management in French companies. Decision Support Systems, 52(4), 828-838.

Li, G., Fan, H., Lee, P. K. C., \& Cheng, T. C. E. (2015). Joint supply chain risk management: an agency and collaboration perspective. International Journal of Production Economics, 164, 83-94.

Mohammaddust, F., Rezapour, S., Farahani, R. Z., Mofidfar, M., \& Hill, A. (2017). Developing lean and responsive supply chains: A robust model for alternative risk mitigation strategies in supply chain designs. International Journal of Production Economics, 183, 632-653.

Nooraie, S. V., \& Parast, M. M. (2015). A multi-objective approach to supply chain risk management: Integrating vis- ibility with supply and demand risk. International Journal of Production Economics, 161, 192-200.

Norrman, A., \& Jansson, U. (2004). Ericsson's proactive supply chain risk management approach after a serious sub-supplier accident. International Journal of Physical Distribution \& Logistics Management, 34, 434-456.

Oliveira, U. R. D., Espindola, L. S., \& Marins, F. A. S. (2017). Analysis of supply chain risk management researches. Gestão \& Produção. Advance online publication.

Pettit, T. J., Fiksel, J., \& Croxton, K. L. (2010). Ensuring supply chain resilience: Development of a conceptual framework. Journal of Business Logistics, 31(1), 1-21.

Ponomarov, S. Y., \& Holcomb, M. C. (2009). Understanding the concept of supply chain resilience. The International Journal of Logistics Management, 20(1), 124-143.

Revilla, E., \& Saenz, M. J. (2017). The impact of risk management on the frequency of supply chain disruptions: a configurational approach. International Journal of Operations \& Production Management, 37(5), 557-576.

Sahay, B. S., \& Ranjan, J. (2008). Real time business intelligence in supply chain analytics. Information Management \& Computer Security, 16(1), 28-48.

Scavarda, L. F., Ceryno, P. Santos, Pires, S., \& Klingebiel, K. (2015). Supply chain resilience analysis: A Brazilian automotive case. RAE-Revista de Administração de Empresas, 55(3), 304-313.

Sheffi, Y., \& Rice Jr., J. B. (2005). A supply chain view of the resilient enterprise. MIT Sloan Management Review, 47(1), 41-48.

Simon, H. A. (1979). Rational decision making in business organizations. American Economic Association, 69(4), 493-513.

Skipper, J. B., \& Hanna, J. B. (2009). Minimizing supply chain disruption risk through enhanced flexibility. International Journal of Physical Distribution \& Logistics Management, 39(5), 404-427.

Sodhi, M. S., Son, B. G., \& Tang, C. S. (2012). Researchers' perspectives on supply chain risk management. Production and operations management, 21(1), 1-13.

Souza, G. C. (2014). Supply chain analytics. Business Horizons, 57(5), 595-605.

Tang, O., Matsukawa, H., \& Nakashima, K. (2012). Supply chain risk management. International Journal of Production Economics, 139(1), 1-2.

Tang, O., \& Musa, S. N. (2011). Identifying risk issues and research advancements in supply chain risk management. International Journal of Production Economics, 133(1), 25-34.

Teo, T. S., Nishant, R., \& Koh, P. B. (2016). Do shareholders favor business analytics announcements? The Journal of Strategic Information Systems, 25(4), 259-276.

Thun, J.-H., \& Hoenig, D. (2011). An empirical analysis of supply chain risk management in the German automo- 
tive industry. International Journal of Production Economics, 131(1), 242-249.

Tomas, R. N., \& Alcantara, R. L. C. (2013). Modelos para gestão de riscos em cadeias de suprimentos: Revisão, análise e diretrizes para futuras pesquisas. Gestão \& Produção, 20, 695-712.

Trkman, P., McCormack, K., Oliveira, M. P. V., \& Bronzo, M. (2010). The impact of business analytics on supply chain performance. Decision Support Systems, 49(3), 318-327.

Tummala, R., \& Schoenherr, T. (2011). Assessing and managing risks using the Supply Chain Risk Management Process (SCRMP). Supply Chain Management: An International Journal, 16(6), 474-483.

Wiengarten, F., Humphreys, P., Gimenez, C., \& McIvor, R. (2016). Risk, risk management practices, and the success of supply chain integration. International Journal of Production Economics, 171, 361-370.
Zhao, L., Huo, B., Sun, L., \& Zhao, X. (2013). The impact of supply chain risk on supply chain integration and company performance: A global investigation. Supply Chain Management, 18(2), 115-131.

Zhu, S., Song, J., Hazen, B. T., Lee, K., \& Cegielski, C. (2018). How supply chain analytics enables operational supply chain transparency: An organizational information processing theory perspective. International Journal of Physical Distribution \& Logistics Management, 48(1), 47-68.

Zsidisin, G. A., \& Ritchie, B. (2009). Supply chain risk management-developments, issues and challenges. In: G. A. Zsidisin, \& B. Ritchie (Eds), Supply Chain Risk: A handbook of Assessment, Management, and Performance (pp. 1-12). Boston, MA: Springer. 